\title{
Inhibited Power Motivation and Persuasive Communication: A Lens Model Analysis
}

\author{
Oliver C. Schultheiss \\ Joachim C. Brunstein \\ University of Potsdam, Potsdam, Germany
}

\begin{abstract}
The authors tested the hypothesis that after motive arousal, individuals with an inhibited power motive (IPM) would excel at a persuasive task and explored the behavioral strategies IPM individuals use to that purpose. Sixty-eight participants presented their point of view on a controversial subject to another person. Power motivation and inhibition were both assessed by a picture-story test. Prior to their presentation, half of the participants imaginatively explored the ensuing task. The other half was assigned to a no-imagery control condition. Lens model analysis of videotaped presentations revealed that IPM participants in the imagery condition were judged to be the most persuasive of all participants. This interactive effect of power motivation, inhibition, and imagery condition was accounted for by three behavioral cues: verbal fluency, gesturing, and
\end{abstract}

Oliver C. Schultheiss and Joachim C. Brunstein, Department of Psychology, University of Potsdam, Potsdam, Germany.

Preparation of this manuscript was facilitated by German Science Foundation Grants SCHU 1210/1-1 and 2-1 to the first author. Portions of this research have been presented at the 105th Annual Convention of the American Psychological Association, Chicago, August 1997. We gratefully acknowledge the help of Petra Rothe in collecting the data and coding the TATs and videotapes, and Ruth Grässmann, Kathrin Mantel, Raïna Tiepke, Arne Weidemann, and Kerstin Sperschneider for rating participants' videotaped presentations.

Correspondence concerning this article should be addressed to Oliver C. Schultheiss, who is now at the Department of Psychology, University of Michigan, 525 East University Ave., Ann Arbor, Michigan 48109-1109. Electronic mail may be sent to oschult@umich.edu.

Journal of Personality 70:4, August 2002.

Copyright (C) 2002 by Blackwell Publishing, 350 Main Street, Malden, MA 02148, USA, and 208 Cowley Road, Oxford, OX4 1JF, UK. 
eyebrow lifts. No comparable effects emerged among no-imagery participants.

By definition, individuals with a strong implicit power motive have an enduring, nonconscious capacity to gain affective pleasure from having impact on other people (McClelland, 1975, 1987; McClelland, Koestner, \& Weinberger, 1989; Winter, 1973). Hence, it seems only natural that high-power persons have been found to climb high on the career ladder, hold offices, become top managers, and make for effective and reputable presidents, all of which gives them ample opportunity to have influence on their social environment and thereby satisfy their power motive (Jenkins, 1994; McClelland, 1975, 1987; Winter, 1973, 1987). But apart from showing that high-power individuals are more likely than others to achieve these life outcomes, research on the power motive has contributed little to our understanding of what the precise behavioral means and strategies are by which these individuals get that far. So how do they do it? And considering the fact that, at least in some individuals, the power motive also has a darker, aggressive, promiscuous, and impulsive side, which would not seem to be conducive to attaining positions of influence and prestige (McClelland, 1987; Winter, 1973), a related question is: Do all power-motivated individuals have whatever it takes to reach these positions, or do only some of them rely on skills that others do not have or utilize?

One hint to answering the first question was given by Veroff (1957), who created the first content-coding system for inferring the strength of an individual's implicit power motive from the imaginative stories she or he produces to picture cues akin to the Thematic Apperception Test (TAT). In a validation study of this scoring system, he found that high-power students, as compared to those low in power, were more likely to be perceived as argumentative and persuasive in class by their instructors. In a similar vein, McKeachie (1961) reported that high-power students were more likely to attain good grades in college courses that fostered participation and student initiative. McKeachie reasoned that such an atmosphere allowed power-motivated students to participate in classroom discussions that would provide an incentive for them to have impact on their fellow students. Thus, there is some evidence suggesting that power-motivated persons may become socially successful because they are good at convincing others. However, 
these studies give no concrete clue as to precisely how high-power individuals are more persuasive than other people.

With regard to the second question, several researchers reported evidence suggesting that activity inhibition is an important moderator of the relation between power motivation and social behavior. Activity inhibition is defined as the degree of restraint a person exercises over expressing emotional-motivational impulses (McClelland, Davis, Kalin, \& Wanner, 1972). The measure originated in computer-based analyses of folk tales, and in studies using the TAT, it is derived from the frequency of the negation not in individuals' stories (e.g., McClelland, 1979). In our own research, we have found the activityinhibition measure to be moderately consistent across stories (Cronbach's alpha $=.55$; Schultheiss \& Brunstein, unpublished data) and to have satisfactory test-retest stability ( $r=.57$ and .51 for a $2-$ and a 4-week interval; Schultheiss \& Dargel, unpublished data). By itself, activity inhibition has been found to predict systolic blood pressure (Fontana, Rosenberg, Marcus, \& Kerns, 1987) and cortisol increases in response to a defeat (Schultheiss \& Rohde, 2002). In combination with high levels of power motivation, high inhibition is related to increased sympathetic nervous system responsivity (McClelland, Floor, Davidson, \& Saron, 1980; McClelland, Ross, \& Patel, 1985), impaired immune system functioning (McClelland et al., 1980, 1985; Jemmott et al., 1983), an increased risk for cardiovascular disease (McClelland, 1979), and severe illnesses (McClelland et al., 1980; McClelland \& Jemmott, 1980). These effects have typically been attributed to a kind of "bottling-up" effect due to which high-inhibition individuals cannot spontaneously vent, and thereby discharge, stress or aroused power motivation. However, the restraint that comes with high levels of inhibition also makes individuals with a strong power motive socially successful: They excel as managers (Jacobs \& McClelland, 1994; McClelland \& Boyatzis, 1982) as well as in other work accomplishments (McClelland \& Franz, 1992), and they are more likely to hold office in voluntary organizations (McClelland \& Pilon, 1983; Winter, McClelland, \& Stewart, 1982). In contrast, low inhibition, combined with a strong power motive, has been linked to excessive drinking (McClelland et al., 1972), physical violence, promiscuous sexual behavior, rejection of institutional responsibility (McClelland, 1975), and testosterone increases and instrumental learning after a victory in a dominance contest (Schultheiss \& Rohde, 2002; see also Schultheiss, Campbell, \& McClelland, 1999). Taken 
together, these findings strongly suggest that individuals with an inhibited power motive (IPM) are more likely than others to rise to leadership positions, whereas individuals with an uninhibited power motive are more prone to express their need for impact in an impulsive and assertive manner which may prevent them from becoming socially successful (cf. McClelland, 1975, 1987; Winter, 1973, 1988). ${ }^{1}$ This would suggest that it is only the former who have acquired the competencies necessary to influence their social environments effectively. Good persuasion skills would presumably be among them, but direct evidence for this notion is lacking.

In the present research, we therefore tested the hypothesis that, as compared to power-motivated individuals low in inhibition or individuals low in power, only IPM individuals will behave in a way that aims at being persuasive and, consequently, will also be perceived as highly persuasive. Therefore, we were not only interested in what kind of impression these individuals made on observers; we also aimed to identify those verbal and nonverbal strategies they used to create that impression. In doing so, we employed a lens model approach that allowed us to test which behaviors would be influenced by participants' personality dispositions and to measure the effects of these behaviors on independent observers' judgments of participants' persuasiveness and personality.

The lens model was conceived by Brunswik (1965) as a framework for the description of inferential processes. Technically, it consists of three components: (a) a distal reality that is not directly accessible to the observer (the left-hand part of the model; the "source" of information) but is encoded in (b) a number of observable cues (the middle part of the model; the actual "lens"), which in turn can be utilized by the observer to arrive at (c) a judgment about the distal reality (the right-hand part of the model; the "reflection" of the original information as "seen" through the lens). The following relations exist between the parts of the model: the degree to which the distal reality is expressed in observable cues, called cue encoding; the

1. We should point out that activity inhibition is by no means "wedded" to the power motive but can moderate the effects of other motives, too. For instance, interactions between activity inhibition and the affiliation motive have been documented in research on abuse in intimate relationships (Mason \& Blankenship, 1987), cardiovascular disease (McClelland, 1979), and immune system functioning (e.g., Jemmott et al., 1983; McClelland \& Kirshnit, 1988). 
degree to which an observer uses available cues to make an inference about the distal reality, called cue decoding; and the degree of congruence between the observer's judgment and the distal reality, called achievement, which is mediated by cues related to both sides of the lens (see Gifford, 1994).

Originally, the lens model was employed by researchers studying the factual basis and accuracy of clinical judgments. As Funder and Sneed (1993) have pointed out, however, it may also be used outside of clinical contexts to promote the integration of personality psychology, which typically focuses only on the left half of the lens by studying how an individual's traits and abilities are expressed behaviorally, and social psychology, which traditionally looks only at the right half of the lens by dissecting which behavioral cues observers use to judge other people. In support of this notion, researchers have successfully used the lens model approach in studies, for instance, on social skills and work motivation (Gifford, $\mathrm{Ng}$, \& Wilkinson, 1985), intelligence (Borkenau \& Liebler, 1992, 1995), trait and circumplex models of personality (Funder \& Sneed, 1993; Gangestad, Simpson, DiGeronimo, \& Biek, 1992; Gifford, 1994), or masculinity and femininity (Lippa, 1998).

To our knowledge, the present research is the first to bring the lens model approach to the study of the behavioral expression of implicit motives and their impact on observers' judgments. It also introduces several methodological advancements over earlier studies (see Figure 1). First, instead of looking only at a single trait, we analyzed how power motivation combines with self-control (i.e., inhibition) to account for an individual's persuasiveness. In doing so, we expected that high inhibition enables power-motivated individuals to express their agentic impulses in socially acceptable ways, such as engaging in persuasive communication as a means of exerting social influence.

Second, we also added an experimentally controlled factor to the person side of the lens model by having half of the participants imaginatively explore the goal of communicating their point of view persuasively before they actually entered the discussion. As we (Schultheiss, 2001; Schultheiss \& Brunstein, 1999) have recently pointed out, implicit motives are aroused by incentives that can be perceived and experienced directly, whereas incentives that are presented and encapsulated in verbal language (as in the case of an experimenter-assigned goal in a psychological laboratory experiment) typically fail to activate implicit motives. We have therefore argued 


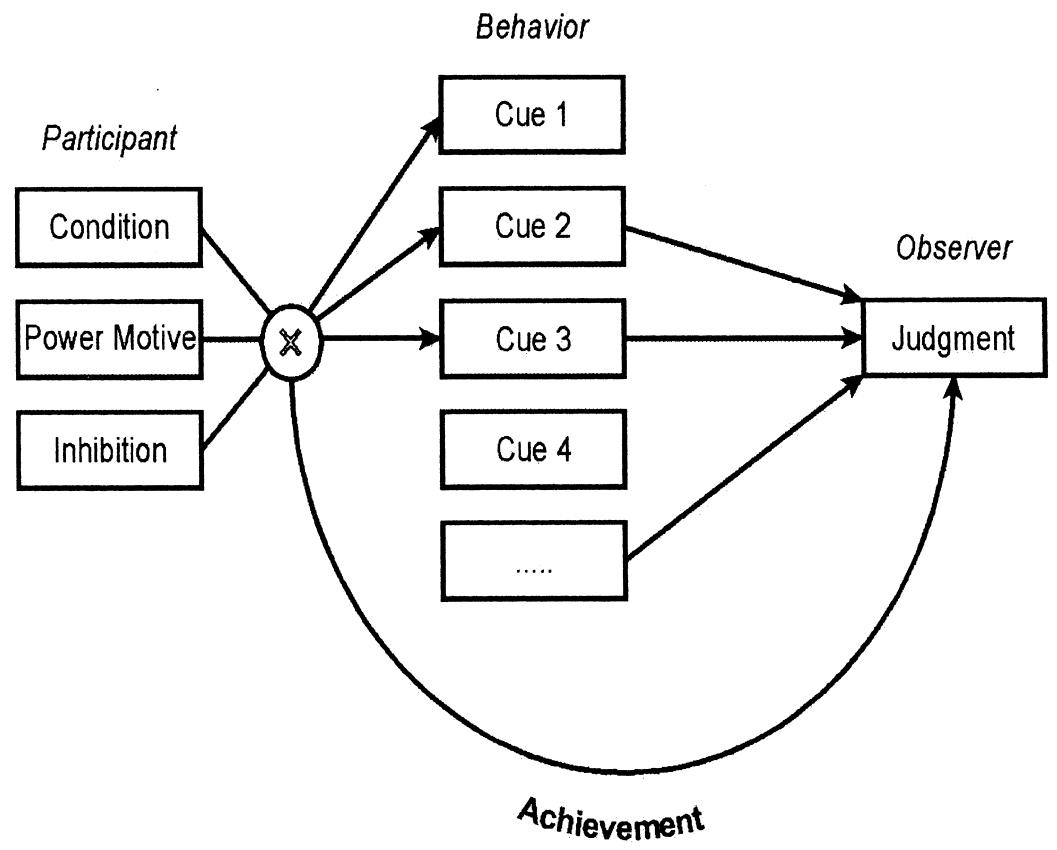

Figure 1

Overview of the lens model employed in this study. We tested whether the triple interaction between participants' experimental condition, power motive, and inhibition would influence participants' behavioral cues (cue encoding), whether these cues would in turn influence observers' judgments of participants' arguments and behavior (cue decoding), and whether the three-way interaction would have a direct effect on these judgments (achievement). We further studied whether behavioral cues related to both sides of the lens would be mediators of the achievement path.

that in order to arouse and engage an individual's implicit motives in a laboratory experiment, the experimenter's verbal goal instructions need to be translated into an experiential format. Based on research indicating that imagining an object or event is neurophysiologically, cognitively, and affectively equivalent to actually perceiving it (reviewed by Schultheiss, 2001), we suggested that vividly imagining the pursuit and attainment of the assigned goal may serve this translational purpose. In support of this notion, we found in our previous research that after participants had been assigned a goal and 
then listened to a tape-recorded goal imagery script which helped them to translate this goal into mental images, their implicit motives had predictable and strong effects on self-reported affective arousal and goal commitment (Schultheiss \& Brunstein, 1999, Study 1), task performance (Schultheiss \& Brunstein, 1999, Study 2), and hormonal changes (Schultheiss et al., 1999). In the absence of goal imagery, however, participants' motives had no detectable impact on dependent variables (Schultheiss \& Brunstein, 1999). Furthermore, we showed that it was the specific motivationally relevant content of the goal imagery exercises that produced this effect, since we failed to find an effect of implicit motives on behavior in participants who had imagined only motivationally neutral aspects of an assigned task (Schultheiss \& Brunstein, 1999, Study 2). The present study therefore aims in part at providing further evidence for the validity and usefulness of the goal-imagery approach to motive arousal by comparing the effects of inhibited power motivation on behavioral outcomes between participants who get an opportunity to explore the assigned goal in their imaginations and those who do not. We expected to observe the predicted IPM effect on persuasive communication only in goal-imagery participants.

Third, we used mediation analysis (Baron \& Kenny, 1986) to test whether identified cues carried the conjoint effect of variables on the person side of the model across to the judgments on the observers' side. This strategy makes it possible to determine whether the achievement path is fully accounted for by the identified cues or whether other, unassessed, cues may be involved in transmitting the effect of a participant's personality to observers' judgments (cf. Lippa, 1998).

To test our hypothesis that IPM individuals are perceived as persuasive communicators, we had each participant present his or her point of view on a controversial subject to another person with whom they expected to discuss the topic after their presentation. Observers later judged participants' videotaped presentations on scales assessing participants' persuasiveness, assertiveness, and sociability-dimensions that could reflect participants' power motivation and level of inhibition. The videotaped presentations were also coded for behavioral cues that, based on past behaviorally oriented research on dominance, influence, and persuasion (e.g., Driskell, Olmstead, \& Salas, 1993; Gifford, 1994; Harper, 1985; Keating, 1985; Mehrabian \& Williams, 1969; Ridgeway, 1987), were expected to represent potential mediators between participants' 
power motivation and observers' judgments of persuasiveness, assertiveness, or sociability. The respective cues covered participants' nonverbal behavior (e.g., eye contact), paralinguistic behavior (e.g., speech fluency), and the content of their presentations (e.g., number of arguments presented).

\section{METHOD}

\section{Participants and Procedure}

Twenty-seven women and 41 men volunteered as participants for the study. The sample consisted of German students and workers. Psychology students were not admitted to the study. The average age of the sample was 25.76 $(S D=3.98)$ years.

Participants were tested individually in sessions that lasted about 80 minutes. At the beginning of the session, the female experimenter administered a TAT measure of motive dispositions to the participants. She then told them that the aim of the study was to identify factors contributing to persuasive argumentation in a discussion. They were to meet another participant with whom they would discuss the subject "Experimentation with animals for scientific and commercial purposes: Is it ethically justified?" We chose this subject for its strongly emotional and polarizing nature. Moreover, the controversy surrounding animal experimentation had received a lot of coverage in the German media in recent years. These factors helped to ensure that a participant was rather opinionated about the discussion's subject from the start, could draw on a wealth of public/factual as well as private/ emotional information to flesh out his or her argument, and could not necessarily expect the other participant to share the participant's point of view. The experimenter explained that the participants' task would be to present their own points of view on this subject as persuasively as possible to their opponents. She told them that the discussion would be videotaped and asked them for their consent to use the recordings for later analyses, which they all gave. Next, participants listened to a tape-recorded imagery exercise. The experimenter explained that this procedure was designed to help them prepare for the ensuing discussion. She then led them into another room in which a male person - a confederate of the experimenter-was waiting. This person was introduced to the participants as another participant who was to be their opponent in the subsequent discussion. The participant and the confederate were seated at a table, facing each other. A microphone was fixed on the table and two cameras were positioned, one behind each of the discussants, each directed towards the person sitting on the opposite side of the table and thus facing the camera. The experimenter explained that in order to structure the discussion, the participant was to start by giving a thorough 
presentation of her or his point of view on the described subject. The other participant (the confederate) would then present his point of view, whereupon both could freely discuss the subject until they felt they were finished. Before she left the room, the experimenter switched on the cameras. However, only the camera directed towards the real participant and the microphone connected to it actually recorded the participant's verbal and nonverbal behavior.

The participant then presented his or her position on experimentation with animals for as long as she or he wanted to. Meanwhile, the confederate behaved in a passive and "neutral" manner; that is, he sat quietly and erect, hands folded in his lap, looking, but not staring at the participant, with a relaxed facial expression, neither interrupting nor commenting on the participant's argument. After the participant had finished and expected the confederate to present his point of view, the confederate ended the experiment, stopped the video camera, and debriefed the participant thoroughly about the study's nature and aims.

\section{Predictor Variables}

\section{Design}

We used an aptitude-treatment-interaction design in the present study to test the effects of power motivation, inhibition, and experimental condition on a participant's verbal and nonverbal behavior and on observers' judgments of participants' videotaped behavior (cf. West, Aiken, \& Krull, 1996). The factor condition (goal imagery vs. control) determined whether the imagery exercise participants listened to before the discussion consisted of a guided relaxation followed by a goal-imagery exercise (goal imagery) or only of the guided relaxation (control). Participants were randomly assigned to one of the two conditions. Participants' scores on TAT-based measures of power motivation and inhibition were entered as continuous independent variables in subsequent statistical analyses.

\section{Picture Story Exercise}

To assess participants' power motive and level of inhibition, a TAT-type picture-story test was administered using instructions described in Winter (1992). The TAT consisted of the following six picture cues: (a) architect at desk, (b) two women in a laboratory, (c) ship captain, (d) couple on bench by a river, (e) trapeze artists, and (f) couple in a nightclub. With the exception of the last picture, which was taken from McClelland (1975), all pictures are contained in Smith (1992).

The resulting TAT protocols were content coded for power motive imagery according to Winter's (1991) Manual for Scoring Motive Imagery in 
Running Text, which allows for scoring of various kinds of motive imagery at once and has been used in previous research on implicit motives (e.g., Brunstein, Schultheiss, \& Grässmann, 1998; King, 1995; Peterson \& Stewart, 1993). According to this manual, the power motive is scored whenever a story character shows a concern with having an impact through strong, forceful actions, controlling, influencing, helping, impressing, or eliciting emotions in others. Two trained scorers, who had demonstrated percentage agreement of $85 \%$ or above with calibration materials prescored by experts, scored the protocols independently. Percentage agreements between scorers for the protocols, calculated according to the formula provided by Winter $(2 \times$ number of agreements between scorers / [scorer A's scores + scorer B's scores]), were $83 \%$ for power motive imagery. Scoring disagreements were resolved by discussion, and scores from these joint sessions were used as participants' final scores. To create an index of participants' levels of inhibition, one scorer also counted how often the German negation nicht (English: not; cf. McClelland, 1979) occurred in each participant's TAT protocol. Mean scores were 4.19 for power $(S D=2.36)$ and 6.07 for inhibition $(S D=3.47)$. We corrected participants' power motive and inhibition scores by regression for protocol length $(M=555$ words, $S D=127)$ and converted them to $z$-scores (cf. Smith, Feld, \& Franz, 1992).

\section{Condition}

The imagery exercise started with a guided relaxation, in the course of which participants were asked to close their eyes and keep them closed throughout the exercise, to focus their attention on various parts of their body, and to relax their muscles. Whereas the imagery exercise ended after that for control group participants, the goal-imagery participants' tape continued with a description of a possible course of the ensuing discussion. The opponent's gender was not identified by the imagery script. Participants were asked to imagine how they would start the discussion by giving an overview of their main arguments on the subject. However, throughout the first minutes of the discussion, the other person signals nonverbally that he or she has an opinion totally different from that of the participant. But the participant does not get discouraged and tries to convince the other person by laying out his or her arguments in greater detail. After some time, the other person becomes uncertain, which again is conveyed to the participant through the person's nonverbal behavior. When the participant eventually finishes her or his argumentation, he or she feels that the other person will have a hard time mustering comparably convincing facts and arguments in defense of her or his own point of view.

The construction and presentation of the imagery script followed the principles described in Schultheiss and Brunstein (1999). The total duration 
of the imagery exercise was about 4 minutes for control group participants and 13 minutes for goal-imagery group participants.

After the exercise had ended, goal-imagery group participants were asked to indicate on a checklist which of six sense modalities (visual, auditory, kinaesthetic, cutaneous, olfactory, and gustatory) had been involved in their imagery while listening to the tape. On average, participants' mental pictures during the guided imagery were anchored in 2.88 sense modalities $(S D=1.17$, Min $=1, \operatorname{Max}=5)$. This indicates that the imagery exercise effectively evoked perception-like experiences in the participants.

\section{Behavioral Cues}

Three raters, who were blind with regard to participants' experimental condition and motive scores, analyzed the videotapes of participants' arguments for a variety of behaviors. Rater A and rater B coded each participant's complete argument for various nonverbal and verbal behaviors that could be observed directly in terms of occurrence or duration. Lowfrequency behaviors and behaviors that, although occurring rather frequently in some participants, a large percentage of participants did not show at all and that thus were not normally distributed and could not be normalized, were transformed into dichotomous measures in which below-median frequencies were coded 0 , and at- or above-median frequencies were coded 1. To obtain the correlation coefficients as estimates of interrater-reliability for all coded behaviors reported in the following paragraph, both raters independently coded the arguments of ten participants for all targeted behaviors (all $p$ s $<.01$ ).

The behaviors measured by these raters were Time talking (the duration from the very first to the very last word of a participant's argument; $M=119, S D=75, r=.99$; this variable was normalized by a logtransformation for all further analyses), number of arguments (defined as the number of clearly discernible issues participants presented during their argument, $M=7.41, S D=3.72, r=.99$ ), argument sidedness (percentage of arguments in favor of experimentation with animals, $M=48 \%, S D=30 \%$. $r=.97$ ), argument balance (derived from sidedness, this measure could range between a maximum of 50 if a participant presented exactly as many proarguments as con-arguments and a minimum of 0 if a participant presented only pro- or only con-arguments, $M=24.85, S D=16.06, r=.92$ ), direct address (i.e., directly addressing the opponent during the argument, a behavior $27 \%$ of all participants engaged in at least once, $r=1.00$ ), eye contact (a percentage measure, created from the overall time participants spent looking at their opponent, divided by time talking and multiplied by $100, M=48.43 \%, S D=19.50 \%, r=.97$ ), eyebrow lifts (observed at least 
once in $46 \%$ of all participants, $r=.76$ ), frowns (observed at least once in $27 \%$ of all participants, $r=1.00$ ), smiles (observed at least once in $49 \%$ of all participants, $r=1.00$ ), arm wrap (observed at least once in $22 \%$ of all participants, $r=.80$ ), gesturing (defined as six or more gestures during the argument, a behavior 54\% of all participants engaged in, $r=1.00$ ), object manipulations (e.g., playing with a pen; observed at least once in $43 \%$ of all participants, $r=1.00$ ), self-manipulations (e.g., scratching one's arm; observed at least once in $62 \%$ of all participants, $r=.80$ ), seating position (an average measure of participants' forward lean [1], erect position [2], and backward lean [3], weighted by the time they spent in each position, $M=1.75, S D=0.84, r=.99$ ), and position change (a change from one seating position to another; observed at least once in $21 \%$ of all participants, $r=.82)$.

Viewing a one-minute slice of each participant's argument, raters B and $\mathrm{C}$ then independently rated the participant's speech characteristics on four items with a 7-point bipolar response format. Interrater reliability for each item was estimated by the correlation between both raters' judgments across all participants (all ps < .00005), and each item was averaged across both raters. The scales assessed speed (endpoints labeled slow vs. fast, $M=4.28, S D=0.95, r=.67$ ), volume (quiet vs. loud, $M=3.74$, $S D=1.24, r=.80$ ), smoothness (halting vs. smooth, $M=4.21, S D=1.24$, $r=.68$ ), and variability (monotone vs. melodic, $M=4.27, S D=0.94$, $r=.50)$. Principal components analysis of these scales with subsequent varimax rotation yielded a two-factor solution according to the scree test. The two factors accounted for $41 \%$ and $39 \%$ of variance. Speed and smoothness comprised the first factor (loadings $>.85$ ) and were combined into an overall measure of verbal fluency. Volume and variability made up the second factor (loadings $>$.79) and were combined into an overall measure of voice modulation.

\section{Observers' Judgments}

Finally, four observers (D, E, F, and G), who were ignorant of the hypotheses guiding this study as well as of the participants' experimental condition and motive scores, independently judged each participant's complete videotaped argument on a series of items with a bipolar 7-point response format (ranging from -3 to 3 ) that were designed to reflect both a participant's success in communicating his or her point of view persuasively and the judges' overall impression of each participant's personality. For each item, interrater reliability across four observers was calculated as the intraclass correlation coefficient according to Shrout and Fleiss' (1979) formula $\operatorname{ICC}(3,1)$ (p. 423; all $p$ s <.01). Each item was subsequently averaged across four observers. 
Observers' judgments of participants' performance in presenting their points of view on experimentation with animals was tapped with the items competence (incompetent vs. competent, $M=0.39, S D=1.01, r=.37$ ), differentiation (one-sided vs. differentiated, $M=0.42, S D=1.25, r=.50$ ), and impact (unimpressive vs. impressive, $M=-0.27, S D=1.16, r=.46$ ). Observers' judgments of participants' personalities were assessed with the items impulsiveness (controlled vs. impulsive, $M=-0.76, S D=1.05$, $r=.40$ ), intelligence (unintelligent vs. intelligent, $M=0.88, S D=0.72$, $r=.32$ ), activity (sluggish vs. active, $M=0.50, S D=0.99, r=.52$ ), agreeableness (awkward vs. agreeable, $M=0.44, S D=0.88, r=.32$ ), dominance (submissive vs. dominant, $M=0.31, S D=0.64, r=.26$ ), joviality (glum vs. jovial, $M=0.56, S D=0.64, r=.44$ ), friendliness (unfriendly vs. friendly, $M=0.91, S D=0.69, r=.34$ ), and extraversion (introverted vs. extraverted, $M=0.52, S D=1.05, r=.51)$.

We subjected observers' judgments of participants' performances and personalities to a principal components analysis followed by varimax rotation. Three factors with an eigenvalue greater than 1 accounted for $48 \%, 23 \%$, and $11 \%$ of the variance. Factor 1 was defined by judgments of extraversion, activity, impulsiveness, and dominance (all loadings $>.77$ ), Factor 2 by judgments of competence, differentiation, impact, and intelligence (all loadings $>$.78), and Factor 3 by judgments of participants' friendliness, joviality, and agreeableness (all loadings $>.75$ ). We therefore computed three separate measures reflecting participants' overall assertiveness (Cronbach's $\alpha=.89$ ), persuasiveness (Cronbach's $\alpha=.90$ ), and sociability (Cronbach's $\alpha=.86$ ) by adding up the scales constituting Factors 1 through 3 .

\section{RESULTS}

Focusing on our double aim of identifying those observer judgments that captured the hypothesized effect of participants' personality dispositions and experimental condition on the one hand and uncovering the behavioral cues that mediated this effect on the other, we pursued the following strategy in the analyses reported below. In a first step, we tested which measures of observers' judgments carried the hypothesized Condition $\times$ Power Motive $\times$ Inhibition interaction (the achievement path in Figure 1). In a second step, we identified those behavioral cues that predicted the judgment measure(s) influenced by the three-way interaction effect (the cue decoding path in Figure 1). In a third step, we analyzed which of the behavioral cues singled out in the second step also carried the Condition $\times$ Power Motive $\times$ Inhibition interaction and were thus potential mediators of 
the predictors' conjoint effect on observers' judgments (the cue encoding path in Figure 1). In a final set of analyses, we tested whether theses cues in fact accounted for the achievement path between participants' personalities and observers' judgments. Because participant gender did not significantly moderate the effects emerging from our lens model analysis, this variable will not be included in the statistical analyses reported below. Correlations among study variables are displayed in Table 1.

\section{Achievement: Predicting Observers' Judgments From Participants' Power Motive, Inhibition, and Experimental Condition}

We subjected judgments of persuasiveness, assertiveness, and sociability to multiple regression analyses in which the simple and combined effects of the predictors were entered simultaneously (cf. Table 2). The hypothesized triple interaction was significant for persuasiveness, and the complete set of predictors accounted for a sizable and significant portion of variance in this variable. If, in addition, time talking was partialled out, the three predictors' conjoint effect remained significant for persuasiveness, $p=.02$. In contrast, variations in assertiveness and sociability were not accounted for by the simple or combined effects of the predictor variables, and the total variance explained by the predictors was small and not significant. To illustrate the significant three-way interaction on persuasiveness, we computed predicted values of the dependent variables for hypothetical goal-imagery and control group participants one standard deviation above (high) or below (low) the power motive and inhibition sample means using $b$ s from the full simultaneous regression equations presented in Table 2 .

The triple interaction on persuasiveness could be traced back to a significant Power Motive $\times$ Inhibition effect in the goal-imagery group, $b=2.83, S E=0.82, t(1,30)=3.45, p=.001$, that did not emerge in the control group, $p>.20$ (simple effects were held constant here as well as in all other follow-up analyses reported below). As depicted for the goal-imagery group in Figure 2, observers judged those high-inhibition participants high in power to have delivered the most persuasive argument and those low in power to have delivered the least persuasive argument of all participants. In contrast, lowinhibition participants were judged to be less persuasive if they were 


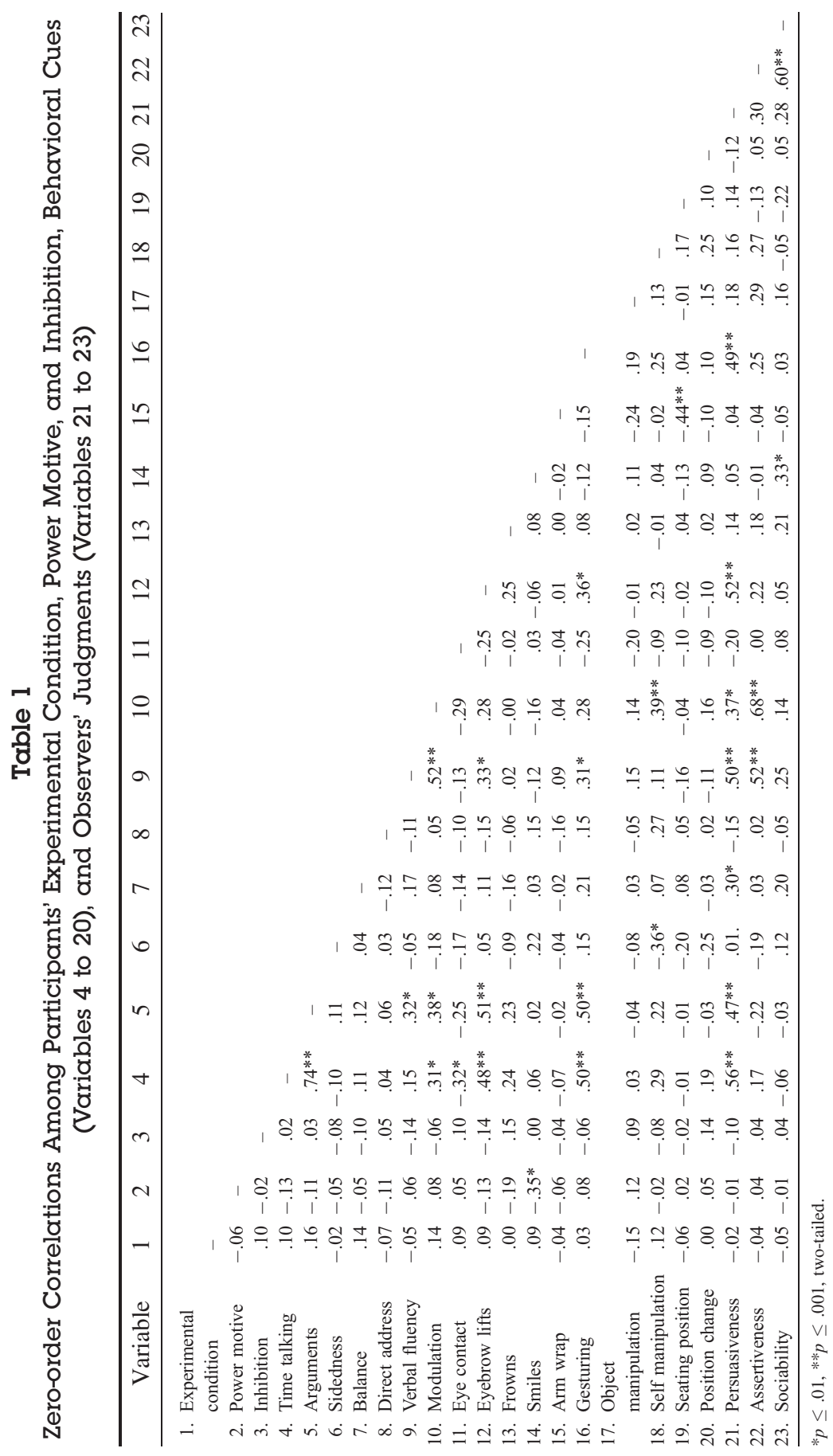


high in power than if they were low in power. In comparison, controlgroup participants' power motive and inhibition levels had very little influence on judged persuasiveness.

\section{Cue Decoding: Predicting Observers' Judgments From Participants' Behavior}

To determine which cues observers used to judge participants' persuasiveness (i.e., the measure that carries the predictors' conjoint influence), we computed correlation coefficients for persuasiveness and each of the 17 behavioral cues (cf. Table 1). Significant predictors of judged persuasiveness were time talking, arguments, argument balance, verbal fluency, voice modulation, eyebrow lifts, and gesturing. Thus, observers judged those participants to be persuasive who talked for a long time, presented many and well-balanced

\section{Table 2}

Multiple Regression Analyses of Judged Persuasiveness, Assertiveness, and Sociability on Participants' Experimental Condition, Power Motive, and Inhibition

\begin{tabular}{|c|c|c|c|c|c|c|}
\hline \multirow[b]{2}{*}{ Variables entered } & \multicolumn{2}{|c|}{ Persuasiveness } & \multicolumn{2}{|c|}{ Assertiveness } & \multicolumn{2}{|c|}{ Sociability } \\
\hline & $b$ & $S E$ & $b$ & $S E$ & $b$ & $S E$ \\
\hline Condition & -.01 & .11 & -.03 & .12 & -.06 & .13 \\
\hline Power Motive & -.03 & .12 & .04 & .13 & -.01 & .14 \\
\hline Inhibition & -.04 & .12 & .04 & .13 & .04 & .14 \\
\hline \multicolumn{7}{|l|}{ Condition } \\
\hline $\begin{array}{l}\times \text { Power Motive } \\
\text { Condition }\end{array}$ & .19 & .12 & -.01 & .13 & -.04 & .14 \\
\hline$\times$ Inhibition & .08 & .12 & .26 & .13 & .17 & .14 \\
\hline \multicolumn{4}{|l|}{ Power Motive } & .15 & .09 & .16 \\
\hline $\begin{array}{l}\text { Condition } \\
\times \text { Power Motive } \\
\times \text { Inhibition }\end{array}$ & $.36^{* *}$ & .14 & .11 & .15 & .04 & .16 \\
\hline $\begin{array}{l}\text { Total variance } \\
\text { explained }\end{array}$ & $R^{2}=$. & & $R^{2}=$ & & $R^{2}=$ & \\
\hline
\end{tabular}

Note. Inhibition, power motive, and all dependent variables were transformed to $z$-scores prior to analysis; experimental condition was effects-coded.

$* p \leq .05, * * p \leq .01, * * * p \leq .005$. 

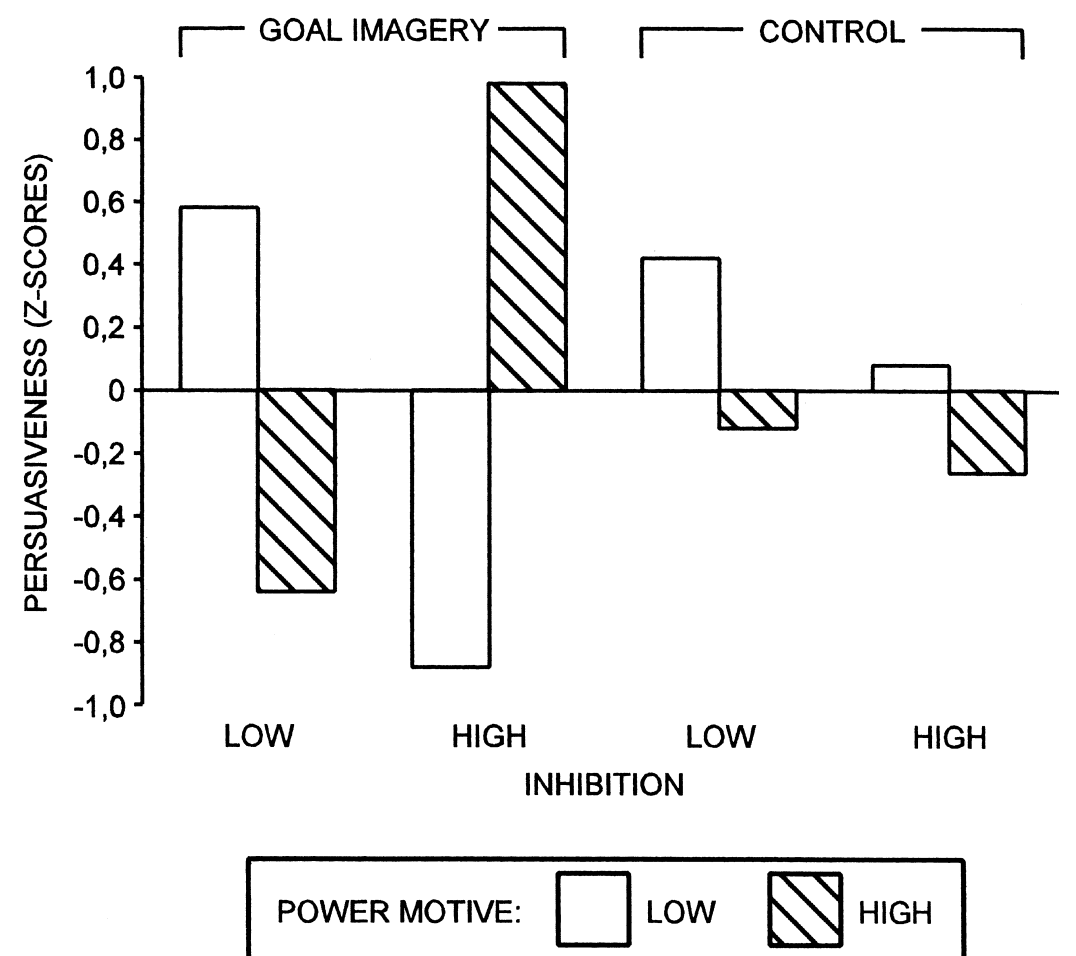

Figure 2

Judged persuasiveness as a function of experimental condition, power motive, and inhibition, computed for values $1 S D$ above (high) or below (low) the means of the personality variables.

arguments, spoke in a fluent and melodious voice, raised their eyebrows, or gestured a lot. Together, these cues accounted for $56.46 \%$ of variance in persuasiveness, $F(7,60)=11.11, p<.000001$.

\section{Cue Encoding: Predicting Participants' Behavior \\ From Their Power Motive, Inhibition, and Experimental Condition}

Regression equations for all variables that were (a) predictors of judged persuasiveness and (b) carried a significant Condition $\times$ Power Motive $\times$ Inhibition effect are reported in Table 3 . We calculated effect-size estimates for the complete regression equations as $R^{2}$ for least-squares regression analyses and $R h o^{2}$ for logistic regression analyses. The latter 


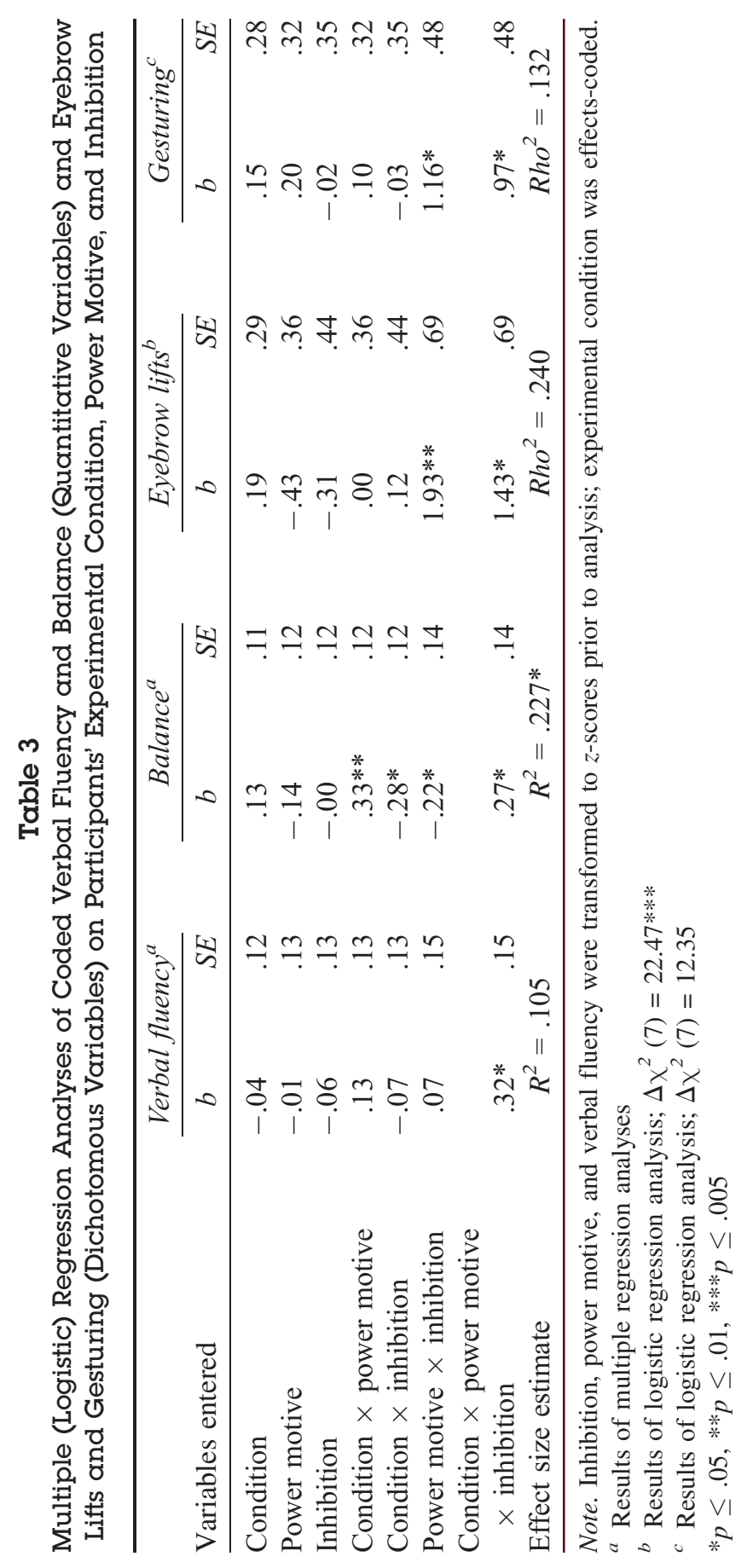


coefficient is based on the difference between the log likelihoods before and after inclusion of the predictors and can vary between 0 (no above-chance prediction of group membership) and 1 (perfect prediction of group membership). To illustrate the significant threeway interactions, we computed predicted values of the dependent variables for hypothetical goal-imagery and control group participants one standard deviation above (high) or below (low) the power motive and inhibition sample means, using $b$ s from the full simultaneous regression equations presented in Table 3 (see Figure 3, Panels A to D; cf. Cohen \& Cohen, 1983; DeMaris, 1992).

\section{Verbal Fluency}

As depicted for the goal imagery condition on the left-hand side of Panel A, high-inhibition participants spoke fluently only if they were also high
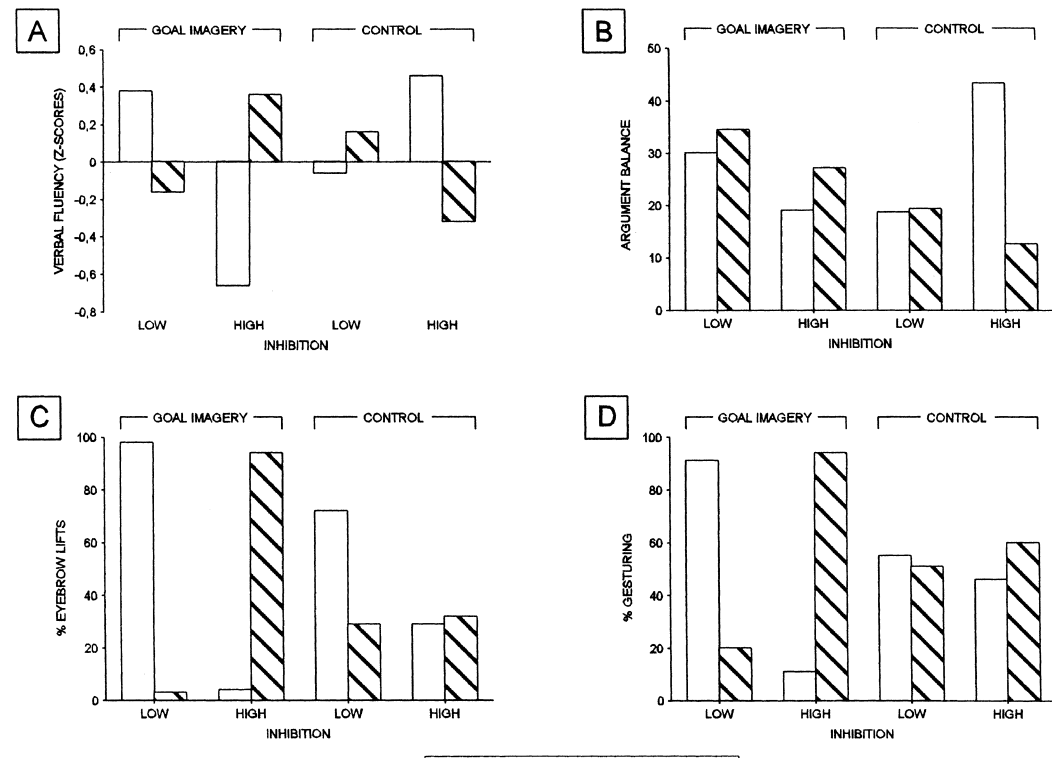

POWER MOTIVE: $\square$ LOW

\section{Figure 3}

Verbal fluency (Panel A), argument balance (Panel B), eyebrow lifts (Panel C), and gesturing (Panel D) as a function of experimental condition, power motive, and inhibition, computed for values $1 S D$ above (high) or below (low) the means of the personality variables. 
in power and least fluently of all participants if they were low in power. Among low-inhibition participants, the power motive had no comparably strong influence on verbal fluency. In contrast, no interaction between participants' power motive and inhibition levels emerged for control-group participants. Accordingly, we found a significant Power Motive $\times$ Inhibition interaction for the goal imagery group, $b=0.77$, $S E=0.43, t(1,30)=1.78, p<.09$, but not for the control group, $p>.20$. Simple effects were not significant in the control group, $p s>.20$.

\section{Balance}

Among goal imagery participants, we found no significant interaction between power motive and inhibition, $p>.20$. However, among control group participants, those low in power and high in inhibition delivered more balanced arguments than all others, as indicated by a significant two-way interaction, $b=-7.84, S E=2.47, t(1,30)=$ $-3.18, p<.005$ (see Panel B).

\section{Eyebrow Lifts}

The triple interaction of the predictors on eyebrow lifts reported in Table 3 survived partialling out time talking, $p<.05$, and was based on a strong Power Motive $\times$ Inhibition effect in the goal-imagery group, $b=3.35, S E=1.31, t(1,30)=2.56, p=.01$, which did not emerge for the control group, $p>.20$. Panel $\mathrm{C}$ shows that in the goal-imagery group, among high-power participants, almost all of those high in inhibition and almost none of those low in inhibition displayed repeated eyebrow lifts, whereas the complete reverse was true for lowpower participants. No comparable pattern could be observed in the control group, although, just as in the goal-imagery group, a rather large percentage of low-inhibition, low-power participants tended to lift their eyebrows repeatedly.

\section{Gesturing}

Covarying out time talking left the Condition $\times$ Power Motive $\times$ Inhibition on Gesturing interaction reported in Table 3 intact, $p<.05$. The triple interaction was rooted in a strong Power Motive $\times$ Inhibition interaction in the goal-imagery group, $b=2.12, S E=0.86$, $t(1,30)=2.40, p=.01$, that did not reach significance in the control 
group, $p>.20$. As depicted in Panel $\mathrm{D}$, among high-power goalimagery participants, almost all of those high in inhibition and only few of those low in inhibition engaged in a lot of gesturing during their arguments, whereas the opposite was true for low-power participants. In the control group, about half of all participants were strong gesturers, regardless of their power motive or inhibition levels. ${ }^{2}$

\section{Mediational Analyses: Can the Identified Behavioral Cues Account for the Achievement Path?}

Finally, following the guidelines for mediational analyses formulated by Baron and Kenny (1986), we tested for goal-imagery group participants whether those behavioral cues that (a) carried the Power Motive $\times$ Inhibition interaction and (b) were significant predictors of judged persuasiveness actually mediated the conjoint influence of a participant's personality on observers' judgments of persuasiveness. The logic underlying this approach is that if the inclusion of a set of behavioral cues in a regression of observers' judgments on the twoway effect of participants' power motive and inhibition-net of simple effects-renders the interaction term nonsignificant, then these behavioral cues are the ones that stamp the effect of participant's personality onto observers' judgments.

Behavioral cues that carried the Power Motive $\times$ Inhibition on Persuasiveness interaction found for goal-imagery participants were verbal fluency, eyebrow lifts, and gesturing. Moreover, judged persuasiveness was significantly correlated with verbal fluency $(r=$ $.62)$, eyebrow lifts $(r=.66)$, and gesturing $(r=.61)$ in this group, $p$ s $<$ .0005 . After controlling for verbal fluency, eyebrow lifts, and gesturing, the conjoint effect of power motive and inhibition on persuasiveness was no longer significant, $t<1, p>.50$. Thus, in the goal-imagery group, in which persuasive impact was significantly predicted by the confluence of power motive and inhibition, verbal fluency, eyebrow

2. In addition, we found significant Condition $\times$ Power Motive $\times$ Inhibition effects for the following behaviors: eye contact $(b=-493.93, S E=144.16, t(1,60)=-3.43$, $p=.001$; full model $\left.R^{2}=.262\right)$, smiles $(b=-.72, S E=.39, t(1,60)=-1.84, p=.07$; full model $\left.R h o^{2}=.148\right)$, and self manipulations $(b=1.11, S E=.54, t(1,60)=2.07, p$ $<.05$; full model $\left.R h o^{2}=.149\right)$. However, since these variables did not predict perceived persuasiveness, we did not include them in the lens model. 
lifts, and gesturing were the behavioral cues that fully transmitted the effect of the participants' personalities on judges' ratings.

\section{DISCUSSION}

Two major results emerged from our present study. First, in support of our main hypothesis, individuals who had explored the assigned persuasive communication task imaginatively and who were characterized by an IPM presented their point of view on a controversial subject more persuasively than any other group of participants, as judged by external observers. Their persuasiveness ratings were far superior to those of individuals high only in power or in inhibition, whose presentations were the least persuasive of all participants, and somewhat better than the above-average ratings of participants low in both dispositional variables.

Second, we also identified three behavioral strategies that transmitted the effect of individuals' personalities to judges' persuasiveness ratings for participants in the goal-imagery group. IPM individuals, as well as individuals low in power and inhibition, spoke more fluently and were more likely to lift their eyebrows and to gesture a lot than other participants, and this in turn contributed to their high persuasiveness ratings. Fluent speech and gesturing have been described as factors contributing to perceived persuasiveness in earlier research (e.g., Mehrabian \& Williams, 1969; Miller, Maruyama, Beaber, \& Valone, 1976; Sorrentino \& Boutillier, 1975), and although eyebrow lifts may also be a nonverbal means of threatening or intimidating another person, the precise meaning of that gesture is largely determined by the context in which it is displayed. Within the context of presenting an argument, an eyebrow lift may serve to emphasize the importance of a point one is making and thus also become a heuristic for observers to judge the weight, and therefore the persuasiveness, of a person's argumentation (cf. Eibl-Eibesfeldt, 1995). Therefore, by displaying these three behaviors, IPM individuals chose strategies that effectively increased the perceived persuasiveness of their argument.

The almost complete lack of influence of personality variables on an individual's behavior and judges' ratings in the control group and the strong effects of participants' personalities on dependent variables in the goal-imagery group supports the notion that implicit motives operate at a nonverbal-experiential, as opposed to a verbal-symbolic, 
level (Epstein, 1994; McClelland, Koestner, \& Weinberger, 1989; Schultheiss, 2001; Schultheiss \& Brunstein, 1999). Both groups were verbally instructed as to the behavioral goal they were to pursue in the subsequent task (i.e., convincing another person of one's point of view on a controversial topic), but only the goal-imagery group had the opportunity to experience this goal in a perception-like way by means of the goal-imagery exercise. Therefore, only goal-imagery participants, but not control-group participants, could process the impact incentive inherent in the assigned goal in a nonverbal-experiential mode. Whether this kind of processing then resulted in high or low levels persuasive communication depended on participants' implicit power motives and inhibition levels. Our results are in keeping with the notion that it takes both the need for impact inherent in a strong power motive and the ability to constrain the assertive impulses flowing from that motive and divert them to socially accepted ways of influencing others to perceive the persuasion task as a power incentive. Thus, the assigned goal matched the needs of IPM individuals but not those of individuals with an uninhibited power motive who prefer to have impact in more unconstrained situations (cf. McClelland et al., 1972).

Unexpectedly, we also found some evidence that imaginatively exploring an assigned goal may elicit impact-directed action tendencies even in the absence of a strong power motive. In goalimagery participants who lacked an intrinsic need for impact, lower levels of activity inhibition predicted more eyebrow lifts, gesturing, verbal fluency and, ultimately, higher persuasiveness ratings. While this unpredicted finding may simply represent a random effect that may not be replicated in future studies, it may also suggest a role for inhibition to regulate motivational impulses in the absence of a strong motivational disposition. In fact, if one assumes that goal imagery has the capacity to elicit some amount of motivation even in individuals low in a particular motivational disposition (representing a motivational induction effect similar to the motivation training techniques described by McClelland, 1987), the "releasing" influence of low activity inhibition on persuasive communication observed in lowpower goal-imagery participants supports the notion that high activity inhibition restrains an individual's motivational impulses from becoming expressed. The picture is a different one for the effect of inhibition on the expression of motivational impulses fueled by an underlying strong motive disposition, as our findings for high-power goal-imagery participants show. Here, activity inhibition seems to be 
more of a moderator of what type of situation a motive responds to and what kinds of behaviors it becomes expressed in than an airtight seal on one's motivational impulses. Clearly, though, these conclusions are purely speculative at this point, and more research is needed to shed light on the role of activity inhibition in motivation and behavior. The present findings do suggest, however, that activity inhibition is a moderator of behavior in its own right and deserves further investigation to clarify its construct validity and its relationship to other constructs in personality research (see also Fontana et al., 1987).

Two other findings merit discussion. First, although goal-imagery participants with an IPM were judged to give the most persuasive presentations of all participants, we did not find any evidence suggesting that these individuals necessarily also presented better or more qualified arguments. ${ }^{3}$ While we cannot rule out at present that more in-depth analyses of argument content may uncover dimensions of discourse through which IPM individuals may have been more persuasive than others, we believe that this finding speaks to the nonverbal, implicit nature of motives. Since motives are assumed to operate at a nonsymbolic, emotional level (McClelland et al., 1989; Schultheiss, 2001; Schultheiss \& Brunstein, 1999), it seems plausible that they are expressed in nonverbal or paralinguistic behavior accompanying a verbal message rather than in the content of the message itself. Clearly, this assumption warrants further research.

Second, we found no evidence that a participant's power motive, either by itself or in combination with inhibition, experimental condition, or both, was associated with judges' ratings of the participant's assertiveness or sociability. Thus, participants with an

3. One reviewer suggested that goal-imagery group participants with an IPM communicated their point of view more persuasively not so much because their implicit motives had been aroused by the goal-imagery exercise but because they may have taken advantage of the time allotted by the goal-imagery exercise to mentally plan and rehearse their line of argumentation for the ensuing discussion. We believe that this explanation is unlikely since we did not obtain any evidence that goal-imagery participants in general or IPM participants in particular presented more or better arguments than control-group participants. It also seems unlikely in light of our finding that goal-imagery participants reported an average of three sense modalities to be engaged by the imagery exercise in the present study and our earlier demonstration that implicit motives predict behavior only after motivespecific goal imagery, but not after motivationally neutral imagery (Schultheiss \& Brunstein, 1999). 
aroused IPM were not judged to be more dominant (a strategy that could backfire if it elicits reactance in others; see, for instance, Driskell et al., 1993; Ridgeway, 1987) or less sociable than other participants in our study, but apparently achieved their aim of having impact upon others in a more subtle way, namely, by exerting influence over others' opinions and attitudes. This finding suggests that the inaccessibility of a person's implicit power motive to her or his introspection (e.g., King, 1995) generalizes to the interpersonal domain; that is, just as individuals are typically unable to give veridical reports on the strength of their implicit power motive, they may also be unable to assess accurately the strength of this motive in others by watching their behavior. This finding also suggests that implicit motives may operate based on a functionality principle according to which behavioral strategies that are instrumental in obtaining and consummating a motive-specific incentive (such as being persuasive in order to have impact) are more likely to be learned and employed than strategies that do not meet this criterion. Since these strategies must not necessarily directly express the goal they are aimed at, a power-motivated person could even strike others as being anything but dominant, while he or she is actually seeking to have impact in a number of ways.

One might speculate that this functionality principle sets implicit motives apart from expressive traits such as extraversion or dominance that may be more directly accessible to both an individual's introspection and observers' judgments. As other research using lens modeling has demonstrated, observers can readily decode an individual's self-ascribed traits from her or his behavior (e.g., Borkenau \& Liebler, 1992; Funder \& Sneed, 1993; Gangestad et al., 1992). Although in the present study we have not assessed participants' traits along with their implicit motivational dispositions to estimate the differential impact of the two kinds of measures on behavioral cues and observers' ratings of functional and expressive aspects of participants' performances, it would be desirable to do so in future research.

\section{Limitations and Future Directions}

Besides the need to replicate the findings of this study in samples differing from ours with regard to age, race, and educational as well as socioeconomical background, we believe that it may be especially 
worthwhile to study the effects of the IPM on perceived persuasiveness in populations with a distinctly different cultural background. Although an extensive body of research on implicit motives in different sociocultural settings and historic times suggests that these personality dispositions represent universals and are not phenomena that only emerge in one specific setting, it has also been demonstrated that the behavioral manifestations of a given motive may vary from setting to setting (cf. McClelland, 1987). Therefore, we would expect that individuals rooted in a different set of sociocultural rules and norms may either use different behavioral ways to be persuasive or even prefer to satisfy their socialized need for impact in ways other than trying to convince another person of their point of view.

Second, the focus of our present research was on perceived persuasiveness and not on actual success at persuading another person to change her or his point of view or behavior. Thus, although the triangulation of Veroff's (1957) and McKeachie's (1961) findings with the results of the present study would strongly suggest that IPM individuals may be highly skilled at influencing other people's attitudes, the nexus between perceived persuasiveness and actual persuasion needs to be established in future research.

Third, in addition to the control group, which did not engage in a goal-imagery exercise in our experimental design, we only included a success-oriented goal-imagery exercise in the goal-imagery condition. Future research might therefore benefit from adding an additional goal-imagery condition in which participants are led to dwell on the possibility of failing at persuading another person. One could thus test if and how the valence of goal-imagery will affect participants' behavior and persuasive impact.

Finally, the results of the present study have helped illuminate some of the ways through which IPM individuals may have social success, but our experimental task has provided no incentives for individuals with an uninhibited power motive. Accordingly, it was not suited to study either the behavioral strategies these individuals use to have impact or what kind of effect they have on others. However, employing a lens model approach in combination with the goal-imagery technique in studies designed to offer incentives for impulsive power motivation would enhance researchers' ability to reveal the behavioral correlates and social consequences of the power motive in action.

To conclude, we believe that the present research brings us closer to understanding both which power-motivated individuals are likely to 
become socially successful and what behavioral strategies they use in order to be successful. As we have demonstrated, IPM individuals are more adept than most at appearing persuasive and convincing to others, and they achieve this effect primarily through nonverbal behavioral means. At the same time, this study also illustrates the usefulness of the lens model approach to deciphering motivated behavior and its impact on the social environment.

\section{REFERENCES}

Baron, R. M., \& Kenny, D. A. (1986). The moderator-mediator variable distinction in social psychological research: Conceptual, strategic, and statistical considerations. Journal of Personality and Social Psychology, 51, 1173-1182.

Borkenau, P., \& Liebler, A. (1992). Trait inferences: Sources of validity at zero acquaintance. Journal of Personality and Social Psychology, 62, 645-657.

Borkenau, P., \& Liebler, A. (1995). Observable attributes as manifestations and cues of personality and intelligence. Journal of Personality, 63, 1-25.

Brunstein, J. C., Schultheiss, O. C., \& Grässmann, R. (1998). Personal goals and emotional well-being: The moderating role of motive dispositions. Journal of Personality and Social Psychology, 75, 494-508.

Brunswik, E. (1965). The conceptual framework of psychology. In O. Neurath (Ed.), International encyclopedia of unified science (4th ed., Vol. 1, No. 10, pp. 1-102). Chicago: University of Chicago Press.

Cohen, J., \& Cohen, P. (1983). Applied multiple regression/correlation analysis for the behavioral sciences (2nd ed.). Hillsdale NJ: Erlbaum.

DeMaris, A. (1992). Logit modeling: Practical applications. Newbury Park CA: Sage.

Driskell, J. E., Olmstead, B., \& Salas, E. (1993). Task cues, dominance cues, and influence in task groups. Journal of Applied Psychology, 78, 51-60.

Eibl-Eibesfeldt, I. (1995). Die Biologie des menschlichen Verhaltens: Grundriß der Humanethologie [The biology of human behavior: Principles of human ethology] (3rd ed.). München: Piper.

Epstein, S. (1994). Integration of the cognitive and the psychodynamic unconscious. American Psychologist, 49, 709-724.

Fontana, A. F., Rosenberg, R. L., Marcus, J. L., \& Kerns, R. D. (1987). Type A behavior pattern, inhibited power motivation, and activity inhibition. Journal of Personality and Social Psychology, 52, 177-183.

Funder, D. C., \& Sneed, C. D. (1993). Behavioral manifestations of personality: An ecological approach to judgmental accuracy. Journal of Personality and Social Psychology, 64, 479-490.

Gangestad, S. W., Simpson, J. A., DiGeronimo, K., \& Biek, M. (1992). Differential accuracy in person perception across traits: Examination of a functional hypothesis. Journal of Personality and Social Psychology, 62, 688-698.

Gifford, R. (1994). A lens-mapping framework for understanding the encoding and decoding of interpersonal dispositions in nonverbal behavior. Journal of Personality and Social Psychology, 66, 398-412. 
Gifford, R., Ng, C. F., \& Wilkinson, M. (1985). Nonverbal cues in the employment interview: Links between applicant qualities and interviewer judgments. Journal of Applied Psychology, 70, 729-736.

Harper, R. G. (1985). Power, dominance, and nonverbal behavior: An overview. In S. L. Ellyson \& J. F. Dovidio (Eds.), Power, dominance, and nonverbal behavior (pp. 29-48). New York: Springer.

Jacobs, R. L., \& McClelland, D. C. (1994). Moving up the corporate ladder: A longitudinal study of the leadership motive pattern and managerial success in women and men. Consulting Psychology Journal Practice and Research, 46, $32-41$.

Jemmott, J. B., Borysenko, J. Z., Borysenko, M., McClelland, D. C., Chapman, R., Meyer, D., \& Benson, H. (1983). Academic stress, power motivation, and decrease in secretion rate of salivary secretory immunoglobulin A. Lancet, 8339, 1400-1402.

Jenkins, S. R. (1994). Need for power and women's careers over 14 years: Structural power, job satisfaction, and motive change. Journal of Personality and Social Psychology, 66, 155-165.

Keating, C. F. (1985). Human dominance signals: The primate in us. In S. L. Ellyson \& J. F. Dovidio (Eds.), Power, dominance, and nonverbal behavior (pp. 89-108). New York: Springer.

King, L. A. (1995). Wishes, motives, goals, and personal memories: Relations of measures of human motivation. Journal of Personality, 63, 985-1007.

Lippa, R. (1998). The nonverbal display and judgment of extraversion, masculinity, femininity, and gender diagnosticity: A lens model analysis. Journal of Research in Personality, 32, 80-107.

Mason, A., \& Blankenship, V. (1987). Power and affiliation motivation, stress, and abuse in intimate relationships. Journal of Personality and Social Psychology, 52, 203-210.

McClelland, D. C. (1975). Power: The inner experience. New York: Irvington Publishers.

McClelland, D. C. (1979). Inhibited power motivation and high blood pressure in men. Journal of Abnormal Psychology, 88, 182-190.

McClelland, D. C. (1987). Human motivation. New York: Cambridge University Press.

McClelland, D. C., \& Boyatzis, R. E. (1982). Leadership motive pattern and long-term success in management. Journal of Applied Psychology, 67, 737-743.

McClelland, D. C., Davis, W. N., Kalin, R., \& Wanner, E. (1972). The drinking man. New York: Free Press.

McClelland, D. C., Floor, E., Davidson, R. J., \& Saron, C. (1980). Stressed power motivation, sympathetic activation, immune function, and illness. Journal of Human Stress, 6, 11-19.

McClelland, D. C., \& Franz, C. E. (1992). Motivational and other sources of work accomplishments in mid-life: A longitudinal study. Journal of Personality, 60, 679-707.

McClelland, D. C., \& Jemmott, J. B. (1980). Power motivation, stress and physical illness. Journal of Human Stress, 6, 6-15.

McClelland, D. C., \& Kirshnit, C. (1988). The effect of motivational arousal through films on salivary immunoglobulin A. Psychology and Health, 2, 31-52. 
McClelland, D. C., Koestner, R., \& Weinberger, J. (1989). How do self-attributed and implicit motives differ? Psychological Review, 96, 690-702.

McClelland, D. C., \& Pilon, D. A. (1983). Sources of adult motives in patterns of parent behavior in early childhood. Journal of Personality and Social Psychology, 44, 564-574.

McClelland, D. C., Ross, G., \& Patel, V. (1985). The effect of an academic examination on salivary norepinephrine and immunoglobulin levels. Journal of Human Stress, 11, 52-59.

McKeachie, W. J. (1961). Motivation, teaching methods, and college learning. In M. R. Jones (Ed.), Nebraska Symposium on Motivation (Vol. 9, pp. 111-142). Lincoln, NE: University of Nebraska Press.

Mehrabian, A., \& Williams, M. (1969). Nonverbal concomitants of perceived and intended persuasiveness. Journal of Personality and Social Psychology, 13, 37-58.

Miller, N., Maruyama, G., Beaber, R. J., \& Valone, K. (1976). Speed of speech and persuasion. Journal of Personality and Social Psychology, 34, 615-624.

Peterson, B. E., \& Stewart, A. J. (1993). Generativity and social motives in young adults. Journal of Personality and Social Psychology, 65, 186-198.

Ridgeway, C. L. (1987). Nonverbal behavior, dominance, and the basis of status in task groups. American Sociological Review, 52, 683-694.

Schultheiss, O. C. (2001). An information processing account of implicit motive arousal. In M. L. Maehr \& P. Pintrich (Eds.), Advances in motivation and achievement (Vol. 12: New directions in measures and methods, pp. 1-41). Greenwich, CT: JAI Press.

Schultheiss, O. C., \& Brunstein, J. C. (1999). Goal imagery: Bridging the gap between implicit motives and explicit goals. Journal of Personality, 67, 1-38.

Schultheiss, O. C., Campbell, K. L., \& McClelland, D. C. (1999). Implicit power motivation moderates men's testosterone responses to imagined and real dominance success. Hormones and Behavior, 36, 234-241.

Schultheiss, O. C., \& Rohde, W. (2002). Implicit power motivation predicts men's testosterone changes and implicit learning in a contest situation. Hormones and Behavior, 41, 195-202.

Shrout, P. E., \& Fleiss, J. L. (1979). Intraclass correlation: Uses in assessing rater reliability. Psychological Bulletin, 86, 420-428.

Smith, C. P. (Ed.). (1992). Motivation and personality: Handbook of thematic content analysis. New York: Cambridge University Press.

Smith, C. P., Feld, S. C., \& Franz, C. E. (1992). Methodological considerations: Steps in research employing content analysis systems. In C. P. Smith (Ed.), Motivation and personality: Handbook of thematic content analysis (pp. 515-536). New York: Cambridge University Press.

Sorrentino, R. M., \& Boutillier, R. G. (1975). The effect of quantity and quality of verbal interaction on ratings of leadership ability. Journal of Experimental Social Psychology, 11, 403-411.

Veroff, J. (1957). Development and validation of a projective measure of power motivation. Journal of Abnormal and Social Psychology, 54, 1-8.

West, S. G., Aiken, L. S., \& Krull, J. L. (1996). Experimental personality designs: Analyzing categorical by continuous variable interactions. Journal of Personality, 64, $1-48$. 
Winter, D. G. (1973). The power motive. New York: Free Press.

Winter, D. G. (1987). Leader appeal, leader performance, and the motive profiles of leaders and followers: A study of American presidents and elections. Journal of Personality and Social Psychology, 52, 196-202.

Winter, D. G. (1988). The power motive in women - and men. Journal of Personality and Social Psychology, 54, 510-519.

Winter, D. G. (1991). Manual for scoring motive imagery in running text (3rd ed.). Department of Psychology, University of Michigan, Ann Arbor: Unpublished manuscript.

Winter, D. G. (1992). Power motivation revisited. In C. P. Smith (Ed.), Motivation and personality: Handbook of thematic content analysis (pp. 301-310). New York: Cambridge University Press.

Winter, D. G., McClelland, D. C., \& Stewart, A. J. (1982). A new defense of the liberal arts. San Francisco: Jossey-Bass. 